\section{UK studies ways of paying to join Chile observatory}

Natasha Loder, London

British astronomers are bracing

themselves for the project cuts that may be needed if Britain is to join the European Southern Observatory (ESO). This is the eight-member organization that operates the recently opened Very Large Telescope on Mount Paranal in Chile.

The Particle Physics and Astronomy Research Council (PPARC) has already opened negotiations with ESO officials in Munich over possible membership (see Nature 405, 382-383; 2000). It believes that, like space and particle physics before it, the price of worldbeating astronomy is now beyond the reach of individual countries.

But the cost of joining the ESO will be high, with an entry fee of at least $\mathfrak{E 6 0}$ million (US\$90 million) and a further $\mathfrak{E} 12$ million every year. PPARC officials say that entry depends both on whether the government will provide extra funding in the next spending round, and whether it can find about $\mathfrak{E} 7$ million a year from existing operating costs.

There was little dispute over the principle of joining the ESO among 150 astronomers who came together last week at a meeting in London organized by the Royal Astronomical Society. If Britain does not join the $\mathrm{ESO}$, one warned, it would create a "lost generation" of young astronomers.

The question now is how to pay for it. According to Ian Corbett of PPARC, costcutting options include withdrawing from the Anglo-Australian Telescope in New South Wales, Australia, and cutbacks at the Isaac Newton Group of Telescopes in Spain and the United Kingdom InfraRed Telescope and the James Clerk Maxwell Telescope in Hawaii.

One possibility is that Britain might bargain for a reduction in the annual fee with a payment in kind of European access to UK facilities. Several possibilities were raised, including the Visible and Infrared Survey Telescope for Astronomy (VISTA) in Chile.

But Jim Emerson, head of the consortium of UK universities that recently won the bid for the VISTA telescope, pointed out that VISTA is not owned by PPARC but by the consortium, so it "can't just be given away".

Catherine Cesarsky, director general of the ESO, says discussions about trading are premature and that, if any trades are made, they would be only a small part of the overall deal.

\title{
Pasteur Institute to abandon departmental structure?
}

\section{Declan Butler, Paris}

The new head of the Pasteur Institute, one of France's leading biomedical research institutions, has begun a major shake-up.

Philippe Kourilsky took over as directorgeneral of the private institute in Paris earlier this year (see Nature 401, 630; 1999). In a meeting last week with its 1,100 scientists, he outlined a series of plans intended to reinforce central management and remove dead wood. In particular, he is disbanding the institute's vertical system of departments in favour of a more horizontal system organized around projects.

Over the past few months Kourilsky has put in place a new central management structure and recruited heavily. Eleven new divisions have been created corresponding to key activities, including scientific careers, multidisciplinary programmes, technology platforms and relations with France's public research organizations.

The technology platforms division, headed by tuberculosis geneticist Stewart Cole, is intended to provide scientists with centrally run services in genomics, proteomics and bioinformatics. One-time venture capitalist Christian Policard, formerly a member of the board of pharmaceutical company Sanofi-Synthélabo, will head the division of ind ustrial affairs.

The institute needed to be "professionalized", says Kourilsky, adding that he was influenced by a three-year stint in the private sector as director of research at Pasteur Mérieux Connaught.

The most drastic step, announced in January, is a rule stating that laboratories more than 12 years old must make a case for their continued existence or be closed. The measure is being applied retroactively and will affect almost half of the institute's laboratories.

Affected laboratories have until the end of October to put forward proposals. Kourilsky warns that laboratories that propose to continue as they are "run the risk of having their applications rejected". Staff who lose their laboratories will be redeployed.

An international call for proposals will be made in September to create new laboratories of five to six researchers led by young scientists. Ten such laboratories, which will have a lifespan of five years, will be created next year, and the ambition is to create 50 within five years. At present, the institute has around 100 laboratories, each with an average staff of 20 to 25 .

Kourilsky adds that the current systems for evaluating individual laboratories and staff has suffered from "inbreeding". In

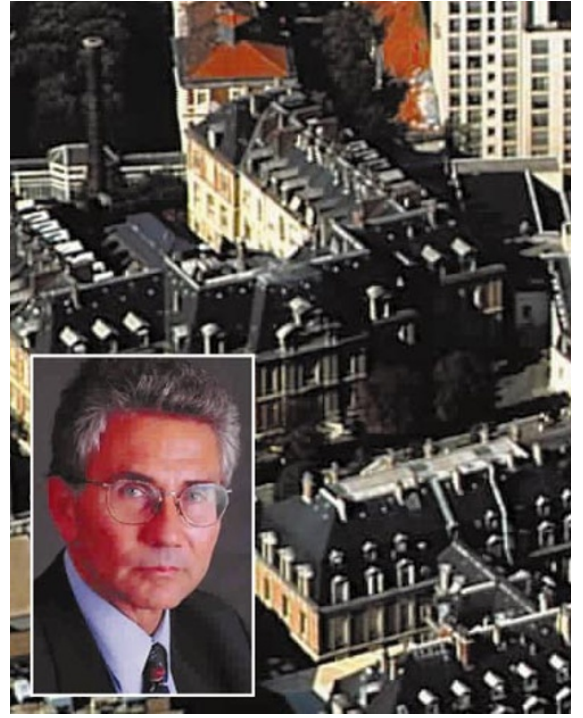

All change: Kourilsky (inset) seeks to increase flexibility at the Pasteur Institute.

future evaluation will be largely carried out by external panels.

A 'foresight' exercise, to be completed by the end of the year, is likely to pave the way for abolition of the institute's ten departments, with projects and programmes between laboratories becoming the main vehicle for implementing research strategy.

Harold Varmus, former director of the US National Institutes of Health and now president of the Memorial Sloan-Kettering Cancer Center in New York, will chair a new eight-member External Committee of Strategic Orientation, intended to provide outside assessment of the institute's general directions.

Kourilsky sees the flexibility allowed by this move as critical to his goal of refocusing the institute on its core mission of combating infectious diseases. At the same time, he has introduced a programme to fund projects spanning the institute's laboratories, which he says have become fragmented.

To force this change, he froze $30 \%$ of laboratory funding at the beginning of the year, to fund a new series of projects that must include at least three of the institute's laboratories. Three-quarters of the laboratories have responded to the call for proposals, and the winners will be announced next month.

So far, researchers at Pasteur seem to be giving Kourilsky the benefit of the doubt; as the institute is private, it has greater freedom to impose reforms. "Change was needed," says one scientist. But there is some scepticism as to how the structural changes will work in practice, given their volume and the proposed speedy timetable. 